\title{
Fabrication and Size-Selective Bioseparation of Magnetic Silica Nanospheres with Highly Ordered Periodic Mesostructure**
}

\author{
By Lei Zhang, Shizhang Qiao, ${ }^{*}$ Yonggang Jin, Huagui Yang, Sandy Budihartono, Frances Stahr, Zifeng Yan, ${ }^{*}$ \\ Xiaolin Wang, Zhengping Hao, and Gao Qing Lu*
}

In this paper, we report a novel synthesis and selective bioseparation of the composite of $\mathrm{Fe}_{3} \mathrm{O}_{4}$ magnetic nanocrystals and highly ordered MCM-41 type periodic mesoporous silica nanospheres. Monodisperse superparamagnetic $\mathrm{Fe}_{3} \mathrm{O}_{4}$ nanocrystals were synthesized by thermal decomposition of iron stearate in diol in an autoclave at low temperature. The synthesized nanocrystals were encapsulated in mesoporous silica nanospheres through the packing and self-assembly of composite nanocrystal-surfactant micelles and surfactant/silica complex. Different from previous studies, the produced magnetic silica nanospheres (MSNs) possess not only uniform nanosize $(90 \sim 140 \mathrm{~nm})$ but also a highly ordered mesostructure. More importantly, the pore size and the saturation magnetization values can be controlled by using different alkyltrimethylammonium bromide surfactants and changing the amount of $\mathrm{Fe}_{3} \mathrm{O}_{4}$ magnetic nanocrystals encapsulated, respectively. Binary adsorption and desorption of proteins cytochrome $c$ (cyt $c$ ) and bovine serum albumin (BSA) demonstrate that MSNs are an effective and highly selective adsorbent for proteins with different molecular sizes. Small particle size, high surface area, narrow pore size distribution, and straight pores of MSNs are responsible for the high selective adsorption capacity and fast adsorption rates. High magnetization values and superparamagnetic property of MSNs provide a convenient means to remove nanoparticles from solution and make the re-dispersion in solution quick following the withdrawal of an external magnetic field.

[*] Prof. Z. F. Yan, L. Zhang

College of Chemistry and Chemical Engineering, China University of Petroleum

Dongying 257061 (China)

E-mail: zfyancat@hdpu.edu.au

Dr. S. Z. Qiao, Prof. G. Q. Lu, L. Zhang, Y. G. Jin, Dr. H. G. Yang, S. Budihartono, F. Stahr

ARC Centre of Excellence for Functional Nanomaterials, School of Engineering and

Australian Institute for Bioengineering and Nanotechnology, The University of Queensland

QLD 4072 (Australia)

E-mail: s.qiao@uq.edu.au, maxlu@uq.edu.au

Dr. X. L. Wang

Spintronic and Electronic Materials Group, Institute for Superconducting and Electronic

Materials, University of Wollongong

NSW 2522 (Australia)

Prof. Z. P. Hao

Research Centre for Eco-Environmental Sciences, Chinese Academy of Sciences

Beijing 100085 (China)

[**] This work was financially supported by the Australian Research Council (ARC) through Discovery Project program (DP0452461), UQ Middle Career Fellowship for SZQ and the ARC Centre of Excellence for Functional Nanomaterials. The authors thank Ms. Pei Yuan and Mr. Yanan Guo of Microscopy and Microanalysis Center, University of Queensland for their part works in TEM characterization. Lei Zhang acknowledges a scholarship from the China Scholarship Council (CSC). Supporting Information is available online from Wiley InterScience or from the authors.

\section{Introduction}

Ordered mesoporous silicas with large surface area and porosity, narrow pore size distribution, controlled morphology, and high thermal and hydrothermal stabilities have been extensively investigated due to their wide potential applications. ${ }^{[1-8]}$ They are considered to be ideal protein and peptide hosts due to their high adsorption capacity, good dispersibility in aqueous solution, and good compatibility with the surrounding environment. ${ }^{[9-16]}$ Such porous materials with tunable pore sizes have been demonstrated to be effective size-selective adsorbents of protein or peptide with different molecular weights based on the size-exclusion mechanism. ${ }^{[10,17-23]}$

For many applications, mesoporous silica spheres with small particle sizes are advantageous from the view of adsorption equilibrium and kinetics. However, it is quite troublesome to separate small particles from liquid. Therefore, magnetic particles have the advantage as they can be conveniently separated from aqueous phase by applying an external magnetic field. Thus, a combination of porous materials and magnetic nanoparticles may be an effective media for separation and has attracted wide attention in recent years. ${ }^{[14,24-29]}$ However, dispersing magnetic nanoparticles in the pores of mesoporous silicas could result in the blocking of pores, lowering surface area, small pore volume, and the distortion of pore structure. ${ }^{[11,24,25,30]}$ In Schuth group's work, magnetic mesoporous silica with an unobstructed pore system was fabricated by grafting magnetic nanocrystals on the outer surface of SBA- 
15. ${ }^{[31]}$ The composites had an irregular shape and size though they could respond to magnetic field well. Uniform magnetic silica nanospheres (MSNs) with a diameter of $270 \mathrm{~nm}$ were prepared by a sol-gel processing of silica on hematite particles followed by $\mathrm{H}_{2}$ reduction. ${ }^{[32]}$ The material had a high magnetization value, but its ferromagnetic property may limit its practical application in some areas. Recently, monodisperse magnetic nanocrystals embedded into the unsymmetrical ordered mesoporous silica spheres with particles size of around $150 \mathrm{~nm}$ were reported. ${ }^{[33]}$ The superparamagnetic characteristics of nanocomposites is advantageous for bioseparation and targeted drug delivery. However, the saturation magnetization values were very low $\left(<2.0 \mathrm{emu} \mathrm{g}^{-1}\right)$ because few magnetic nanocrystals were encapsulated in the silica particles. More recently, Hyeon and coworkers reported a novel synthesis method for uniform magnetic mesoporous silica spheres with superparamagnetic characteristics. ${ }^{[34]}$ But yet again, low saturation magnetization values and randomly aligned mesochannels (disordered mesostructure) did not benefit the potential selective bioseparations. Therefore, it is highly desirable and significant to prepare uniform MSNs with a highly ordered mesostructure, high magnetization value, superparamagnetism, and tuneable pore size for size-selective bioseparation applications.

For the synthesis of MSNs, the preparation of monodisperse magnetic nanocrystals itself is one of the important issues. During the last few years, many researchers have described efficient synthetic routes to prepare shape-controlled, highly stable, and monodisperse magnetic nanoparticles. Several popular methods including co-precipitation, ${ }^{[35-37]}$ micelle synthesis, ${ }^{[38-40]}$ hydrothermal synthesis, ${ }^{[41,42]}$ and thermal decomposition and/or reduction, ${ }^{[43-45]}$ have been applied at the synthesis of magnetic nanoparticles. Co-precipitation is the simplest method for the synthesis of monodisperse nanoparticles. However, the shape control is very difficult with this method. The microemulsion method can be used to synthesize monodispersed nanoparticles with various morphologies. However, this method requires a large amount of solvent. Hydrothermal synthesis produces high-quality nanoparticles, but the yield is very low. Thermal decomposition method has been widely used due to the good performance in size and morphology control of the nanoparticles. However, high temperatures (over $300^{\circ} \mathrm{C}$ ), costly and toxic starting materials are disadvantages of this method.

Herein, we firstly report a novel synthesis of monodisperse superparamagnetic nanocrystals by low temperature $\left(250^{\circ} \mathrm{C}\right)$ thermal decomposition of iron stearate in diol in an autoclave. Using an autoclave and a relatively cheap iron stearate precursor avoids a preparation process of precursor ${ }^{[43]}$ and provides advantages of improved safety, convenience, and savings of time and costs. Then, using these nanocrystals, we successfully synthesized the MSNs with a highly ordered mesostructure. Different from previous studies, the produced MSNs possess not only uniform nanosize $(90 \sim 140 \mathrm{~nm})$ but also highly ordered mesostructure. More importantly, the pore size and the saturation magnetization values are tunable.
Monodispersion, small particle size, narrow pore size distribution, high surface area, large pore volume, and superparamagnetic characteristics may make these MSNs useful in drug delivery, bioseparation, and catalysis. To investigate their applications as a size-selective bioseparation matrix, we selected a mixture of binary proteins with varying size and molecular weight, cytochrome $c$ (cyt $c$ ) and bovine serum albumin (BSA), as model proteins. By studying their adsorption on MSNs, we demonstrated that our MSNs can be used effectively for the size-selective separation of biomolecules with different sizes.

\section{Results and Discussion}

\subsection{Superparamagnetic Nanocrystals}

Monodisperse $\mathrm{Fe}_{3} \mathrm{O}_{4}$ nanocrystals were prepared by thermal decomposition of iron stearic acid at low temperature $\left(250^{\circ} \mathrm{C}\right)$ in an autoclave. As-prepared stearic acid ligand-capped $\mathrm{Fe}_{3} \mathrm{O}_{4}$ nanocrystals were dispersed in nonpolar chloroform solvent. Transmission electron microscope (TEM), High resolution TEM (HRTEM, inset) images, powder X-ray diffraction (XRD) pattern, and the field-dependent magnetization curve at $300 \mathrm{~K}$ of $\mathrm{Fe}_{3} \mathrm{O}_{4}$ nanoparticles are shown in Figure 1. The TEM image displays the highly uniform characteristics of the nanocrystals of $6 \mathrm{~nm}$ in diameter. HRTEM image reveals the highly crystalline nature of the nanocrystals with the $\mathrm{Fd} 3 m$ space group. Powder XRD pattern of a typical sample matches very well with the $\mathrm{Fe}_{3} \mathrm{O}_{4}$ data from JCPDS database (file 19-629). The field-dependent magnetization curve measured at $300 \mathrm{~K}$ shows no hysteresis loop, which is a characteristic of a typical superparamagnetic material. The saturation magnetization value is about $40.6 \mathrm{emu}^{-1}$.

Monodisperse magnetic nanocrystals can be synthesized by the thermal decomposition of organometallic compounds in high-boiling organic solvents containing stabilizing surfactants. ${ }^{[43-45]}$ Compared with the prior art, ${ }^{[43]}$ the reaction in our work here was carried out at a lower temperature of $250^{\circ} \mathrm{C}$ (rather than over $300^{\circ} \mathrm{C}$ ) in a closed autoclave (rather than open environment). The use of an autoclave for thermal decomposition of iron stearate complex provides advantages of improved safety and convenience. Moreover, the iron stearate precursor is commercially available as a fairly cheap industrial feedstock, which represents a saving of time and costs. The superparamagnetic property of nanocrystals is vital to their rapid re-dispersion after the applied magnetic field is removed, which is an advantage to their application to bioseparation.

\subsection{Magnetic Silica Nanospheres with Highly Ordered Mesostructure}

A typical procedure for the synthesis of magnetic nanocrystals embedded in highly ordered periodic mesoporous silica spheres is shown in Scheme 1. Magnetic nanocrystals 

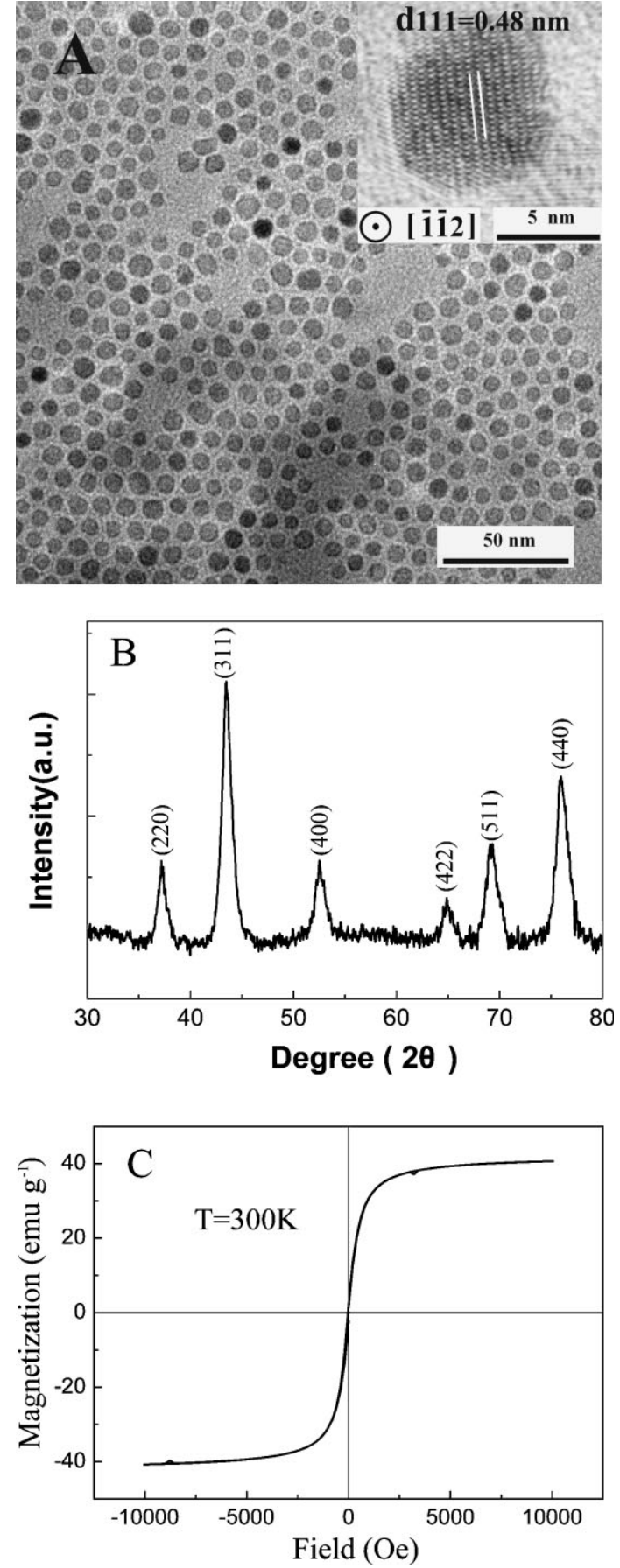

Figure 1. A) TEM and HRTEM (insert) images, B) XRD pattern of monodisperse magnetic nanocrystals, and $\mathrm{C}$ ) Field-dependent magnetization curve at $300 \mathrm{~K}$ of $\mathrm{Fe}_{3} \mathrm{O}_{4}$ nanocrystals.

capped by hydrophobic stearic acid ligands were transferred from chloroform into aqueous solution for being easily embedded in silica spheres during sol-gel hydrolysis and condensation of silica. In this study, myristyltrimethylammonium bromide $\left(\mathrm{C}_{14} \mathrm{TAB}\right)$, hexadecyltrimethylammonium bromide $\left(\mathrm{C}_{16} \mathrm{TAB}\right)$, or octadecyltrimethylammonium bromide

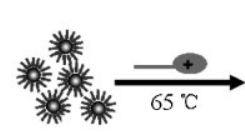

a)
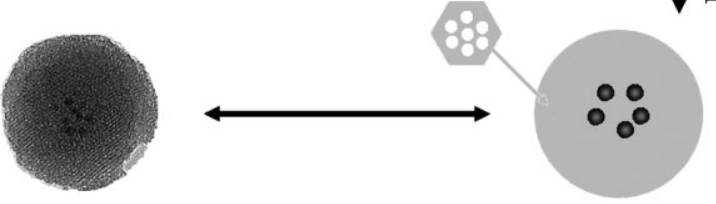

e) b)
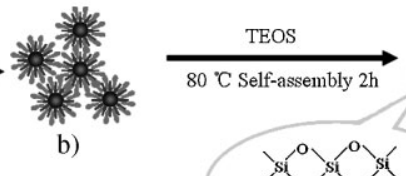

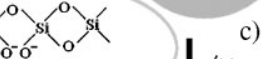

d)

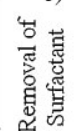

\section{$\bullet=\mathrm{Fe}_{3} \mathrm{O}_{4}$ Nanoparticle 藻 $=\underset{\text { Stearic Acid }}{\mathrm{Fe}_{3} \mathrm{O}_{4} \text { with }} \rightarrow=\mathrm{C}_{\mathrm{X}} \mathrm{TAB}$}

Scheme 1. Synthetic procedure of monodisperse superparamagnetic silica nanospheres.

$\left(\mathrm{C}_{18} \mathrm{TAB}\right)$ was utilized as a surfactant to produce the second layer on the outer surface of magnetic nanocrystals which led to high dispersion of nanocrystals in water ${ }^{[46-48]}$ Then, a silica precursor tetraethoxysilane (TEOS) hydrolyzed, condensed, and made a self-assembly with surfactant micelles to produce surfactant/silica complexes by $\mathrm{S}^{+} \mathrm{I}^{-}$(S: surfactant; I: inorganic species) pathway under basic conditions. MSNs with a highly ordered periodic mesostructure were formed by further packing and crystallization of silica/surfactant complexes around surfactant-nanocrystal micelles at high temperature $\left(80^{\circ} \mathrm{C}\right)$ as well as the subsequent treatment with fluxing ethanol in order to remove surfactant templates. Pore size of MSNs was extended by varying the carbon chain length of surfactant from $\mathrm{C}_{14}, \mathrm{C}_{16}$ to $\mathrm{C}_{18}$.

Scanning electron microscope (SEM) and TEM images of surfactant-extracted MSNs-C $\mathrm{C}_{14}-2$, MSNs- $\mathrm{C}_{16}-2$, and MSNs- $\mathrm{C}_{18}-2$ samples are shown in Figure 2 (in sample $\mathrm{MSNs}_{-}-x, x$ denotes the solution volume of $\mathrm{Fe}_{3} \mathrm{O}_{4}$ nanocrystals added in the synthesis process and $y$ is aliphatic hydrocarbon chain length of surfactant). It can be seen that the sizes of MSNs are quite uniform. The average sizes of MSNs- $\mathrm{C}_{14}-2$, MSNs- $\mathrm{C}_{16}-2$, MSNs- $\mathrm{C}_{18}-2$ vary in a range of ca. $90-140 \mathrm{~nm}$ as observed from the SEM and TEM images. TEM images show that magnetic nanocrystals are successfully embedded in the MSNs, and the silica matrixes of MSNs have highly ordered two-dimensional hexagonal mesostructures.

Low angle XRD patterns of samples MSNs- $\mathrm{C}_{14}-2$, MSNs- $C_{16}-2$, and MSNs- $\mathrm{C}_{18}-2$ are shown in Figure 3A. A high-intensity diffraction peak of (100) and three additional well-resolved diffraction peaks of (110), (200), (210) are observed, which can be assigned to a two-dimensional hexagonal mesostructure (space group p6mm). This suggests a long range ordering of the porous structure and well-formed hexagonal pore arrays. The cell parameter " $a$ " calculated from the diffraction peaks gradually increases with an increase in carbon chain number of surfactants from $\mathrm{C}_{14}$ to $\mathrm{C}_{18}$ (Table 1). 

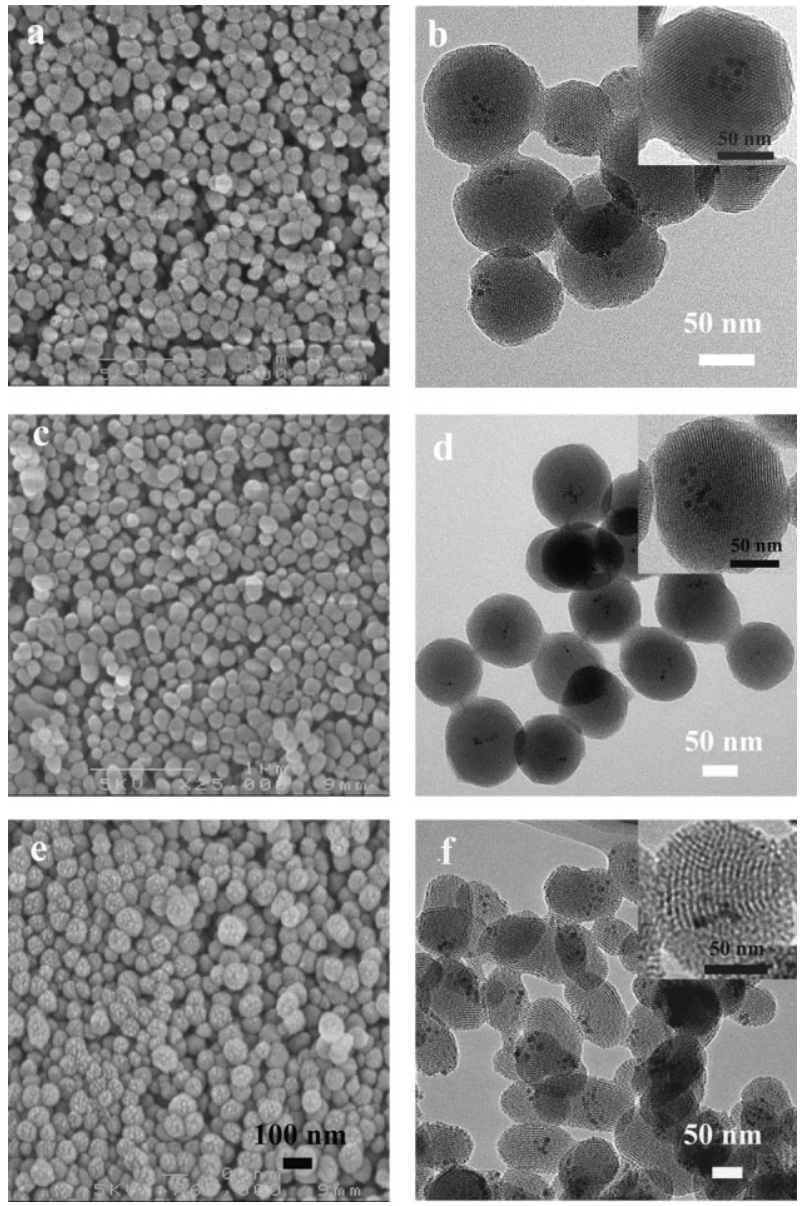

Figure 2. SEM and TEM images of MSNs with different pore sizes: MSNs$\mathrm{C}_{14}-2(\mathrm{a}, \mathrm{b}), \mathrm{MSNs}^{-} \mathrm{C}_{16}-2(\mathrm{c}, \mathrm{d})$, MSNs- $\mathrm{C}_{18}-2(\mathrm{e}, \mathrm{f})$.

Figure $3 \mathrm{~B}$ shows the wide-angle XRD patterns of magnetic nanospheres. The characteristic diffraction peaks of $\mathrm{Fe}_{3} \mathrm{O}_{4}$ with space group $\mathrm{Fd} 3 \mathrm{~m}$ structure are clearly observed, which is consistent with TEM observations and further confirms the existence of magnetic nanocrystals in MSNs.

Nitrogen sorption isotherms of the MSNs samples with variable pore sizes in Figure 4 display typical type IV
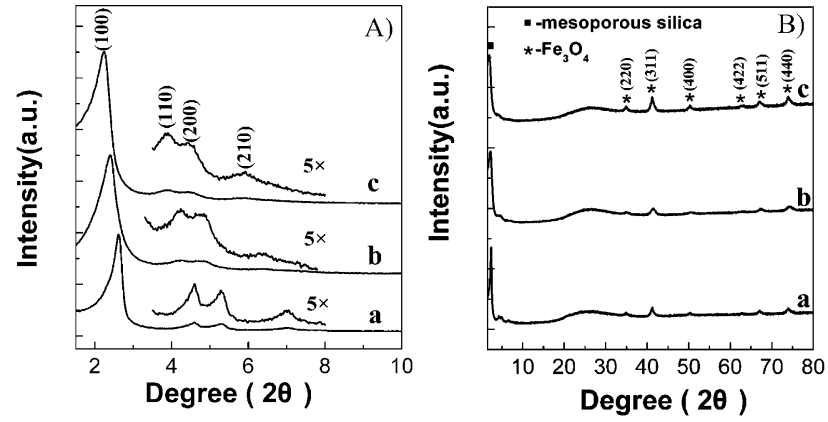

Figure 3. A) low angle and $B$ ) wide-angle $X R D$ patterns of MSNs with different pore sizes: a) MSNs- $\mathrm{C}_{14}-2$, b) $\mathrm{MSNs}^{-} \mathrm{C}_{16}-2$, c) MSNs- $\mathrm{C}_{18}-2$.

adsorption isotherms with type $\mathrm{H} 1$ hysteresis loops which are characteristic of mesostructure with 1-D cylindrical channels. The narrow and sharp pore size distribution curves (inset of Fig. 4) suggest that the mesopores have very uniform sizes. Their structural parameters and the saturation magnetization values are summarized in Table 1 . It can be seen that MSNs- $\mathrm{C}_{14}-2$, MSNs- $\mathrm{C}_{16}-2$, and $\mathrm{MSNs}_{18}-2$ have high BrumauerEmmett-Teller (BET) surface areas $\left(952 \sim 1108 \mathrm{~m}^{2} \cdot \mathrm{g}^{-1}\right)$ and large pore volumes $\left(0.74 \sim 1.14 \mathrm{~cm}^{3} \cdot \mathrm{g}^{-1}\right)$. The pore sizes of samples MSNs- $\mathrm{C}_{14}-2$, MSNs- $\mathrm{C}_{16}-2$, and MSNs- $\mathrm{C}_{18}-2$ are 2.4, 2.8 , and $3.4 \mathrm{~nm}$, respectively, further indicating that the pore sizes of MSNs can be tunable by using different surfactants.

The saturation magnetization values of MSNs can be tunable by varying the amount of $\mathrm{Fe}_{3} \mathrm{O}_{4}$ nanocrystals added in the synthesis process. Typically, MSNs- $\mathrm{C}_{14}-1, \mathrm{MSNs}_{-}-\mathrm{C}_{14}-2$, MSNs- $\mathrm{C}_{14}-3$, and MSNs- $\mathrm{C}_{14}-8$ were prepared by adding $1,2,3$, and $8 \mathrm{~mL}$ of the as-synthesized $\mathrm{Fe}_{3} \mathrm{O}_{4}$ nanocrystals chloroform solution, respectively. SEM and TEM images of samples are shown in Figure 5 (more TEM images in Fig. S1 of Supporting Information). TEM images suggest that the $\mathrm{Fe}_{3} \mathrm{O}_{4}$ nanocrystals are well distributed in silica shells, even though much more $\mathrm{Fe}_{3} \mathrm{O}_{4}$ nanocrystals are embedded. It indicates that the surfactant and stearic acid ligands capped on the surface of $\mathrm{Fe}_{3} \mathrm{O}_{4}$ nanocrystals play important roles not only in transferring nanocrystals from hydrophobic to hydrophilic properties,

Table 1. The structural parameters and saturation magnetization values of MSNs with different pore sizes and magnetite contents.

\begin{tabular}{|c|c|c|c|c|c|c|}
\hline Sample name & $d_{100}[\mathrm{~nm}]$ & $a[\mathrm{~nm}]$ & $S(B E T)\left[\mathrm{m}^{2} \cdot \mathrm{g}^{-1}\right]$ & $V\left[\mathrm{~cm}^{3} \cdot \mathrm{g}^{-1}\right]$ & $D(\mathrm{BJH})[\mathrm{nm}]$ & $\begin{array}{l}\text { Saturation magnetization } \\
\text { value }\left[\mathrm{emu} \cdot \mathrm{g}^{-1}\right]\end{array}$ \\
\hline MSNs- $\mathrm{C}_{14^{-1}}$ & 3.90 & 4.50 & 1317.6 & 0.90 & 2.4 & 0.43 \\
\hline MSNs- $C_{14}-2$ & 3.91 & 4.51 & 952.3 & 0.74 & 2.4 & 2.59 \\
\hline MSNs- $\mathrm{C}_{14}-3$ & 3.95 & 4.56 & 914.0 & 0.72 & 2.4 & 4.06 \\
\hline MSNs- $C_{14}-8$ & 4.00 & 4.62 & 727.9 & 0.71 & 2.4 & 7.62 \\
\hline MSNs- $C_{16}-2$ & 4.17 & 4.82 & 967.8 & 1.05 & 2.8 & 2.63 \\
\hline MSNs-C ${ }_{18}-2$ & 4.60 & 5.31 & 1108.1 & 1.14 & 3.4 & 2.61 \\
\hline
\end{tabular}

$d_{100}$ : the interplanar spacing of the (100) plane. $a$ : the lattice parameter calculated by $a=2 d_{100} / \sqrt{3}$. S(BET): BET surface area calculated using experimental points at relative pressure of $P / P_{0}=0.05-0.25$. V: pore volume, calculated by the $\mathrm{N}_{2}$ amount adsorbed at the highest $P / P_{0}(\sim 0.99)$. $\left.D(B) H\right)$ : pore size, calculated by BJH method. 


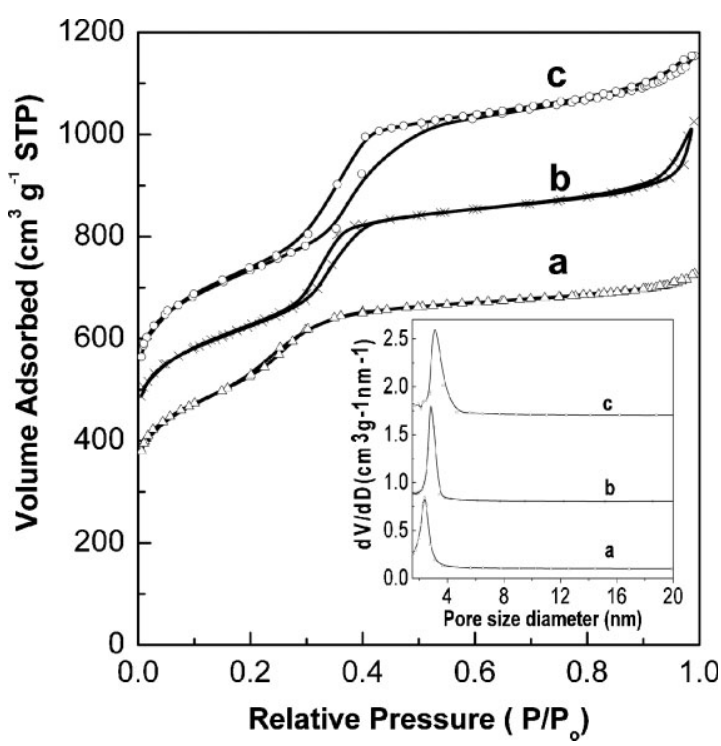

Figure 4. $\mathrm{N}_{2}$ adsorption/desorption isotherms (inset: pore size distribution calculated from adsorption branch) of MSNs with different pore sizes: a) $\mathrm{MSNs}-\mathrm{C}_{14}-2$, b) $\mathrm{MSNs}-\mathrm{C}_{16}-2$, c) $\mathrm{MSNs}-\mathrm{C}_{18}-2$. Isotherms of a), b), and c) have been offset by 265,360 , and $430 \mathrm{~cm}^{3} \mathrm{~g}^{-1}$ along the vertical axis for clarity, respectively.

but also in protecting the aggregation of nanocrystals in the forming process of MSNs. However, as the amount of nanocrystals increases, the mesostructure of silica shells gradually changes from order to disorder (Fig. 5d, inset) because more chloroform is difficult to be evaporated from water which disturbs the packing and self-assembly of surfactant micelles. SEM images show that all samples are uniform spheres and their particle sizes are around 130-
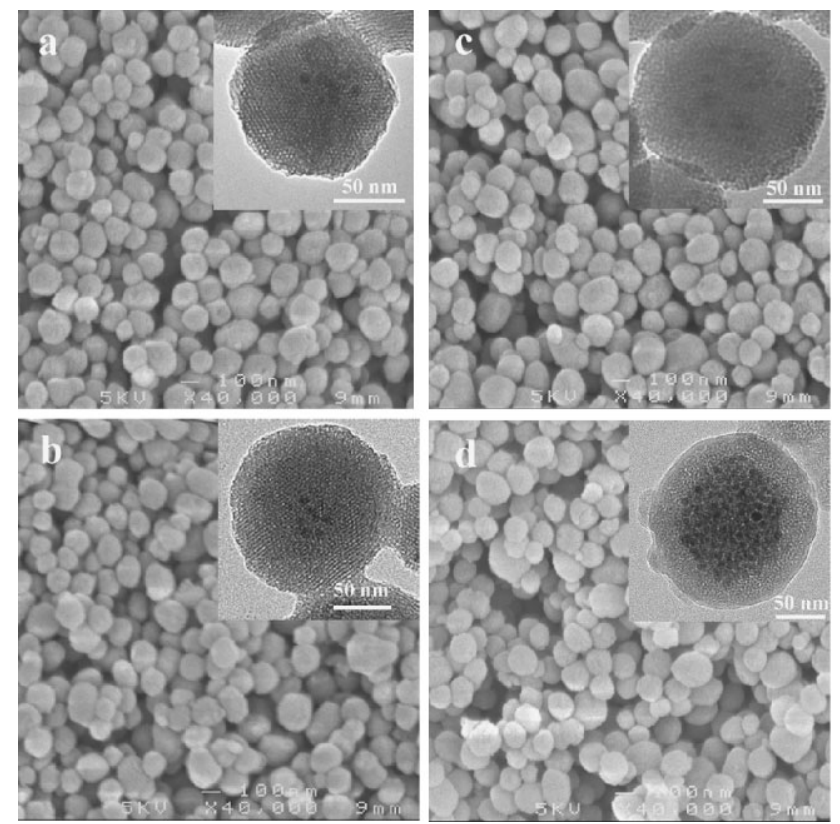

Figure 5. SEM and TEM images (inset) of MSNs with different magnetite values: a) MSNs- $C_{14^{-1}}$, b) MSNs- $\mathrm{C}_{14^{-}}-2$, c) MSNs- $\mathrm{C}_{14^{-}}-3$, and d) MSNs- $\mathrm{C}_{14^{-}-8}$.
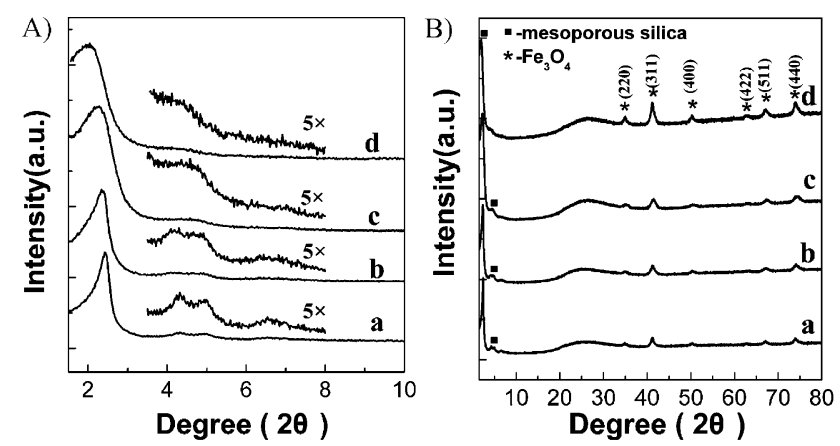

Figure 6. A) Small angle and B) wide-angle XRD patterns of MSNs with different magnetite values: a) MSNs- $\mathrm{C}_{14}-1$, b) MSNs- $\mathrm{C}_{14}-2$, c) $\mathrm{MSNs}-\mathrm{C}_{14}-3$, and d) $\mathrm{MSNs}_{-} \mathrm{C}_{14}-8$.

$150 \mathrm{~nm}$, which does not change with an increase in the amount of $\mathrm{Fe}_{3} \mathrm{O}_{4}$

Figure 6A shows the small angle XRD patterns of samples MSNs-C $_{14}-1$, MSNs- $\mathrm{C}_{14}-2$, MSNs- $\mathrm{C}_{14}-3$, MSNs- $\mathrm{C}_{14}-8$. Four diffraction peaks of the samples MSNs- $\mathrm{C}_{14}-1$ and $\mathrm{MSNs}_{-} \mathrm{C}_{14}-2$ with low amounts of $\mathrm{Fe}_{3} \mathrm{O}_{4}$ nanocrystals, assigned to the (100), (110), (200), and (210) diffractions, reflect a highly ordered two-dimensional hexagonal mesostructure. As the amount of $\mathrm{Fe}_{3} \mathrm{O}_{4}$ nanocrystals increases (samples MSNs- $\mathrm{C}_{14}-3$ and MSNs- $\left.\mathrm{C}_{14}-8\right)$, the (100) diffraction peak widens and the (210) diffraction peak disappears, which indicates that the mesoporous structure becomes nonsymmetrical and poorly ordered. This is in accordance with the TEM observations. The wideangle XRD patterns of these samples (Fig. 6B) display that the intensities of all diffraction peaks increase with an increase in the amount of nanocrystals, suggesting that more nanocrystals are embedded in MSNs. This will be further confirmed and discussed by the magnetism study below.

The nitrogen sorption isotherms of the MSNs- $\mathrm{C}_{14}$ samples with variable magnetite amounts are shown in Figure 7. Similarly, the adsorption isotherms are typical of type IV. The pore sizes, pore volumes, and BET surface areas are also summarized in Table 1. It is interesting to note that the calculated cell parameters and pore sizes are the same for the samples with variable magnetite amounts but the surface areas and pore volumes decrease with an increase in the amount of magnetite nanocrystals. This implies that the existence of nanocrystals does not disturb the packing and self-assembly of silica/surfactant complex. The decrease in surface areas and pore volumes is caused by density increasing with the increase in magnetite amount. The other reason may be the poor order of pores caused by more chloroform addition which is consistent with the observation on a wide pore size distribution (inset of Fig. 7). Even so, the material with a high magnetite amount (MSNs- $\mathrm{C}_{14}-8$ ) still has a high BET surface area of $727.9 \mathrm{~m}^{2} \cdot \mathrm{g}^{-1}$ and a large pore volume of $0.71 \mathrm{~cm}^{3} \cdot \mathrm{g}^{-1}$.

Figure 8 shows the field-dependent magnetization curves of MSNs- $\mathrm{C}_{14}-1$, MSNs- $\mathrm{C}_{14}-2$, MSNs- $\mathrm{C}_{14}-3$, MSNs- $\mathrm{C}_{14}-8$ measured at $300 \mathrm{~K}$. They exhibit a typical feature of superparamagnetism and no hysteresis is observed in low fields. The saturation 


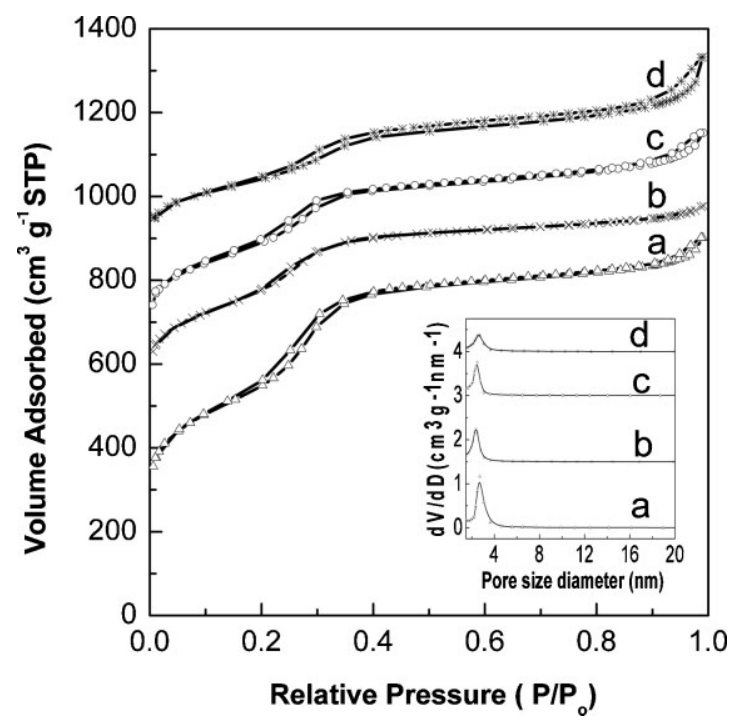

Figure 7. $\mathrm{N}_{2}$ adsorption/desorption isotherms (inset: pore size distribution from adsorption branch) of MSNs with different magnetite values: a) $\mathrm{MSNs}_{-} \mathrm{C}_{14}-1$, b) $\mathrm{MSNs}-\mathrm{C}_{14}-2$, c) $\mathrm{MSNs} \mathrm{C}_{14}-3$, and d) $\mathrm{MSNs}_{-} \mathrm{C}_{14}-8$. Isotherms of a), b), c), and d) have been offset by 200, 515, 670, and $850 \mathrm{~cm}^{3} \mathrm{~g}^{-1}$ along the vertical axis for clarity, respectively.

magnetization value of MSNs-C $\mathrm{C}_{14}-1$ is $0.43 \mathrm{emu} \cdot \mathrm{g}^{-1}$, but it dramatically increases to $2.59 \mathrm{emu} \cdot \mathrm{g}^{-1}$ for $\mathrm{MSNs}_{-} \mathrm{C}_{14}-2$, $4.06 \mathrm{emu} \cdot \mathrm{g}^{-1}$ for $\mathrm{MSNs}-\mathrm{C}_{14}-3$, and $7.62 \mathrm{emu} \cdot \mathrm{g}^{-1}$ for MSNs- $\mathrm{C}_{14}-8$, which further confirms that the magnetization values of MSNs are tunable in a certain range. The MSNs with superparamagnetic characteristics and high magnetization values can quickly respond to the external magnetic field and quickly redisperse once the external magnetic field is removed. This is advantageous for targeted drug delivery and bioseparation applications.

As for the formation mechanism, we propose that the MSNs with highly ordered periodic mesostructures are formed by the packing and self-assembly of composite nanocrystal-surfactant micelles and surfactant/silica complexes. The hydrophobic van

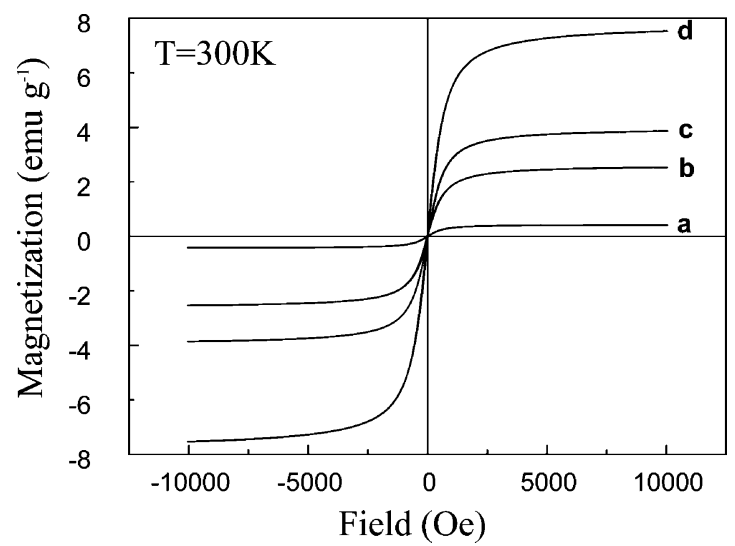

Figure 8. Field-dependent magnetization at $300 \mathrm{~K}$ of MSNs with different amounts of magnetite: a) MSNs- $\mathrm{C}_{14^{-1}}$, b) $\mathrm{MSNs}^{-} \mathrm{C}_{14}-2$, c) $\mathrm{MSNs}^{-} \mathrm{C}_{14}-3$, and d) $\mathrm{MSNs}-\mathrm{C}_{14}-8$. der Waals interactions between the primary alkane of stearic acid on nanocrystal surface and the secondary alkane of the surfactant result in thermodynamically defined interdigitated bilayer structure, which can easily transfer the hydrophobic nanocrystals from solvent phase to aqueous solution. The produced surfactant/stearic acid capped nanocrystals are with positive charges as the amido of cation surfactant. ${ }^{[46]}$ It is well known that, under basic conditions, the hydrolyzed silica and surfactant templates produce complexes and their surfaces are full of silanol groups (Si-OH). ${ }^{[49]}$ The nanocrystal-surfactant micelles can act as a seed to attract the silica/surfactant complexes through electrostatic and hydrogen-bonding interactions, followed by surfactant directed self-assembly of silica/ surfactant mesophases. The detailed explanation is as follows: hydrolyzed TEOS monomers condense to form oligomeric silica precursors. When the oligomeric silica precursors reach a certain size, these precursors and surfactants are assembled to produce small monodisperse mesoporous silica spheres together with nanocrystals-surfactant micelles, and then they emerge in solution. The residual silica/surfactant complexes then react preferentially with the surface silanols on the particles that have been generated, preventing the formation of any extra particles. This leads to the formation of uniform magnetic mesoporous silica nanospheres. Because the basic units of mesostructured materials are silica/surfactant complexes, it is clear that varying the carbon length of cationic surfactants could lead to the formation of MSNs with tunable pore sizes. Nanocrystal-surfactant composite micelles and their further self-assembly with silica into ordered 3D nanocrystals arrays in bulk or thin-film forms as well as magnetic silica spheres with disordered mesoporous structures were reported previously. ${ }^{[34,46]}$ It is worthy to note that this is the first time to encapsulate $\mathrm{Fe}_{3} \mathrm{O}_{4}$ nanocrystals into the silica nanospheres with highly ordered periodic mesostructures, tunable pore sizes, and magnetization values.

Our results show that the MSNs with highly ordered mesostructured silica matrix can be successfully fabricated using $\mathrm{C}_{16}$ or $\mathrm{C}_{18}$ surfactant as a template by sol-gel reaction of TEOS in the sodium hydroxide aqueous solution at a high temperature $\left(80^{\circ} \mathrm{C}\right)$, but it was difficult for $\mathrm{C}_{14} \mathrm{TAB}$ to achieve the self-assembly to produce highly ordered mesoporous matrix at the same conditions, although nanocrystals can be embedded in the silica spheres (Fig. S2 of Supporting Information). Mesoporous phase formation and structural regularity of MCM-41 materials largely depends on the aliphatic hydrocarbon chain length of cationic surfactant. It has been demonstrated that the nanometer-scale structures of the mesoporous materials synthesized by longer carbon chain surfactants are more highly ordered than those prepared by the shorter chain surfactants under the same conditions. ${ }^{[50,51]}$ This is expected because the higher hydrophobicity can lead to longer cylindrical micelles and a well-ordered hexagonal phase. In contrast, the shorter chain surfactants cannot easily aggregate to form long micelles and the micellar surface becomes rough, which leads to worsened packing and poor order in the mesostructure. ${ }^{[50,51]}$ 


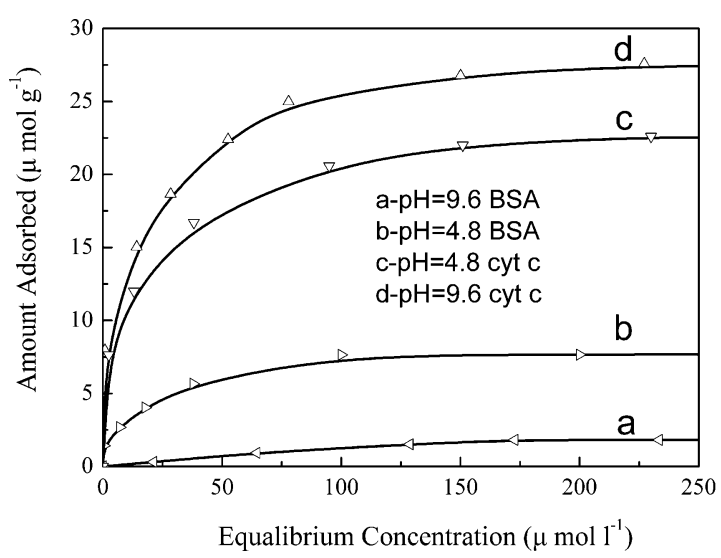

Figure 9. Adsorption isotherms of cyt $c$ and BSA on the sample MSNsC18-2 at different $\mathrm{pH}$ values.

Sol-gel processing temperature plays an important role in the self-assembly of surfactant/silica complexes because the hydrophobic interactions change relative to temperature and the micellization is largely affected by these interactions. For MSNs- $\mathrm{C}_{14}$ synthesis, a low temperature $\left(30^{\circ} \mathrm{C}\right)$ makes $\mathrm{C}_{14} \mathrm{TAB}$ more hydrophobic which may favor a tight aggregation of the surfactant in a micelle and the formation of highly ordered hexagonal phase. It has been reported that the assembly rate of the templating cationic surfactants and the hydrolysis and condensation rates of silica precursor slow down with the decrease in the reaction temperature, which facilitates the fabrication of highly ordered mesoporous silicas ${ }^{[52]}$ and the production of uniform silica nanospheres in the MSNs- $\mathrm{C}_{14}$ synthesis.

The basic catalyst $\mathrm{NaOH}$ or $\mathrm{NH}_{4} \mathrm{OH}$ is another factor in controlling the sol-gel hydrolysis and condensation processes of silica. The previous study demonstrated that the combination of silicate oligomers among the Gouy-Chapman region in the ammonia medium is stronger than that in $\mathrm{NaOH}$, thus, $\mathrm{NH}_{4} \mathrm{OH}$ medium favors the production of longer cylindrical micelles. ${ }^{[53]}$ Therefore, ammonia aqueous solution used in this work may be the other reason to produce highly ordered mesostructure for $\mathrm{C}_{14} \mathrm{TAB}$ surfactant at low temperatures.

\subsection{Bioadsorption Isotherms and Binary Bioseparation}

To investigate MSNs as a size-selective bioseparation matrix, we selected two proteins with varying size and molecular weight, cyt $c$ (MW 12327 , isoelectric point (pI) 9.8 , molecular dimensions $\left.2.6 \times 3.2 \times 3.0 \mathrm{~nm}^{3[54]}\right)$ and BSA (MW 66 000, pI 4.8, molecular dimensions $4.0 \times 4.0 \times 14.0 \mathrm{~nm}^{3[23]}$ ), as model proteins. For adsorption isotherm measurements, $\mathrm{pH}=9.6$ (near the $\mathrm{pI}$ of cyt $c$ ) and $\mathrm{pH}=4.8$ (near the $\mathrm{pI}$ of BSA) were chosen because the adsorption capacity can be maximized near the pI. ${ }^{[2,54,55,56]}$ The experimental adsorption isotherms of cyt $c$ and BSA on MSNs- $\mathrm{C}_{18}-2$ at $30^{\circ} \mathrm{C}$ and both $\mathrm{pH}$ values as well as their fitting curves by Langmuir equation are shown in Figure 9. All isotherms show a sharp initial rise and then reach maximum adsorption amounts (plateau), suggesting that isotherms are of Langmuir type.

At $\mathrm{pH} 9.6$, the maximum adsorbed amount of cyt $c$ is $27.58 \mu \mathrm{mol} \cdot \mathrm{g}^{-1}$, while that of BSA is $1.9 \mu \mathrm{mol} \cdot \mathrm{g}^{-1}$ only. The adsorption of cyt $c$ is typically determined by electrostatic and hydrophobic interactions (a kind of van der Waals attraction). When the solution $\mathrm{pH} 9.6$ is near the $\mathrm{pI}$ of cyt $c$, the net charge of cyt $c$ is near zero. Thus, the electrostatic repulsion between the amino acid residues on the surface of cyt $c$ molecules is very small, and the cyt $c$ molecules can pack closely on the surface of adsorbent pore by hydrophobic interactions. ${ }^{[16]}$ This result is consistent with earlier studies, in which the maximum adsorbed amounts of cyt $c$ on similar MCM-41 materials were 26.6 and $33.7 \mu \mathrm{mol} \cdot \mathrm{g}^{-1}$, respectively. ${ }^{[54,57]}$ The slight adsorption of BSA is the expected result of (i) complete exclusion from the pores of adsorbent because the dimension of BSA $\left(4.0 \times 4.0 \times 14.0 \mathrm{~nm}^{3[23]}\right)$ is larger than pore size of adsorbent $(3.4 \mathrm{~nm})$, (ii) electrostatic repulsion between silica surface (negative charge) and BSA molecules (negative charge), and (iii) electrostatic repulsion among BSA molecules. This indicates that the size selectivity is strict by using MSNs with narrow pore size distribution as an adsorbent to separate cyt $c$ and BSA at $\mathrm{pH}$ 9.6.

In an attempt to evaluate exterior surface adsorption of cyt $c$ and BSA onto MSNs, the as-synthesized MSNs- $\mathrm{C}_{18}-2$ (pores were completely blocked with the surfactant template) was employed for comparison at the same experimental conditions. It was found that only $0.6 \mu \mathrm{mol} \cdot \mathrm{g}^{-1}$ of cyt $c$ was adsorbed on the as-synthesized MSNs- $\mathrm{C}_{18}-2$ at $\mathrm{pH}$ 9.6, which conformed that cyt $c$ was mostly adsorbed onto the intra-pore of MSNs. Meanwhile, it was determined that $1.5 \mu \mathrm{mol} \cdot \mathrm{g}^{-1}$ of BSA was adsorbed on the as-synthesized MSNs- $\mathrm{C}_{18}-2$ at $\mathrm{pH} 9.6$, which conformed that the BSA was mostly adsorbed on the outer surface of MSNs.

At $\mathrm{pH} 4.8$, the adsorbed amounts of cyt $c$ and BSA are 22.5 and $7.6 \mu \mathrm{mol} \cdot \mathrm{g}^{-1}$, respectively. As there is no repulsion

Table 2. Adsorption selectivity and desorption release efficiency of binary cyt c and BSA on MSNs- $\mathrm{C}_{18}-2$.

\begin{tabular}{lccccccc}
\hline $\begin{array}{l}\text { Initial concentration } \\
{\left[\mathrm{g} \cdot \mathrm{L}^{-1}\right]}\end{array}$ & $\begin{array}{c}\text { Equilibrium concen- } \\
\text { tration }\left[\mathrm{g} \cdot \mathrm{L}^{-1}\right]\end{array}$ & & $M_{\text {cyt } c}\left[\mu \mathrm{mol} \cdot \mathrm{g}^{-1}\right]$ & $M_{\mathrm{BSA}}\left[\mu \mathrm{mol} \cdot \mathrm{g}^{-1}\right]$ & Selectivity [\%] & Released in buffer $[\%]$ \\
\hline cyt $c$ & BSA & cyt $c$ & BSA & & & & \\
\hline 0.5 & 1.5 & 0.01 & 1.4 & 7.95 & 0.61 & 92.9 & 96.8 \\
0.5 & 4.5 & 0.01 & 4.3 & 7.95 & 1.21 & 92.4 \\
\hline
\end{tabular}

$M_{\text {cytc }}$ and $M_{\mathrm{BSA}}$ are the molar amount of cyt $c$ and BSA adsorbed on the MSNs, respectively. The selectivity for cyt $c$ was calculated by Equation 2 . 
between the amino acid residues on the surface of adsorbed BSA molecules near the pI, the BSA molecules can pack well on the outer surface of MSNs. As a result, the adsorbed amount of BSA increases near its pI. ${ }^{[23]}$ The adsorbed amount of cyt $c$ decreases below its pI. This behavior is ascribed to the expansion of the effective molecular diameter of cyt $c$ because strong repulsive forces between the amino acid residues of the cyt $c$ molecules are present and more space is needed for the expanded cyt $c$ molecule. ${ }^{[54,55]}$ Another reason may be electrostatic repulsion among cyt $c$ molecules (positive charge).

Based on the adsorption isotherms and discussions above, we demonstrated a real binary adsorption separation process of cyt $c$ and BSA. Table 2 shows the bioseparation results of cyt $c$ and BSA on MSNs- $\mathrm{C}_{18}-2$ at $\mathrm{pH} 9.6$ and $30^{\circ} \mathrm{C}$. Interestingly, the MSNs- $\mathrm{C}_{18}-2$ exhibited a good selectivity for the cyt $c$ separation (93.9 and $86.8 \%$ for different initial concentrations, respectively). More importantly, the release percentages of cyt $c$ from MSNs- $\mathrm{C}_{18}-2$ in high ionic strengths (salt concentration $=1.0 \mathrm{M} \mathrm{KCl})$ buffer $(\mathrm{pH}=9.6)$ at $30^{\circ} \mathrm{C}$ are very high (92 and $93 \%$ for two cases, respectively). Fast removal rate and high removal efficiency are mainly attributed to its high surface area, small particle size, and numerous accessible straight pores. Using the magnetic properties of the MSNs samples, we can easily remove them from solution or redisperse them in solution. Figure 10 displays a detailed separation process. Fresh MSNs- $\mathrm{C}_{18}-2$ is added to the mixed solution of cyt $c$ and BSA. After stirring and static state adsorption for $20 \mathrm{~min}$, MSNs- $\mathrm{C}_{18}-2$ with adsorbed cyt $c$ is separated by a magnetic field which results in high purity of BSA solution. Then, wet MSNs- $\mathrm{C}_{18}-2$ is transferred into high

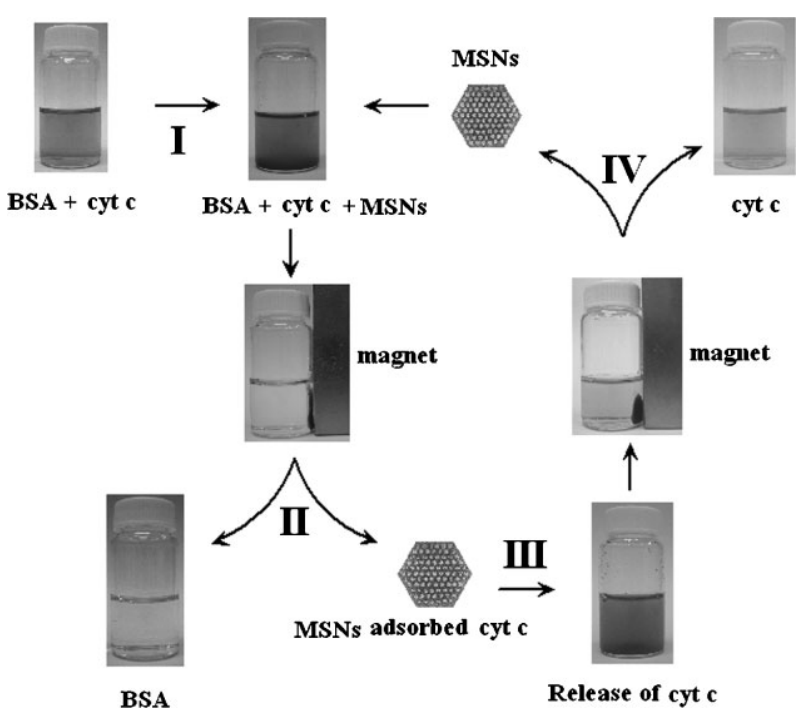

Figure 10. Scheme for the separation of cyt $c$ and BSA by magnetically mobilizing the MSNs- $\mathrm{C}_{18}-2$ sample: a) fresh $\mathrm{MSNs}_{-} \mathrm{C}_{18}-2$ is added to the solution of cyt $\mathrm{c}$ and $\mathrm{BSA}$; b) MSNs- $\mathrm{C}_{18}-2$ with adsorbed cyt $\mathrm{c}$ is separated by a magnetic field, resulting in high purity of BSA solution; $c$ ) MSNs- $\mathrm{C}_{18}-2$ with adsorbed cyt $c$ is transferred into high ionic strength buffer to release the cyt $c$; d) MSNs- $\mathrm{C}_{18}-2$ is separated from solution by a magnetic field for re-use, producing a high purity of cyt $c$ solution. ionic strength buffer to release the cyt $c$. At last, $\mathrm{MSNs}_{18}-2$ is separated from solution by a magnetic field for re-use, which leads to a high purity of cyt $c$ solution.

\section{Conclusions}

Monodisperse superparamagnetic $\mathrm{Fe}_{3} \mathrm{O}_{4}$ nanocrystals of uniformly $6 \mathrm{~nm}$ in diameter were prepared by thermal decomposition of inexpensive iron stearic acid at $250^{\circ} \mathrm{C}$ in a closed autoclave, which constitutes an economic, safe and environment friendly synthesis method of magnetic nanocrystals. The composite of $\mathrm{Fe}_{3} \mathrm{O}_{4}$ magnetic nanocrystals and MCM-41 type periodic mesoporous silica nanospheres were successfully synthesized. Detailed characterization studies show that MSNs have highly ordered mesostructure, quite uniform small particle sizes, high surface areas, large pore volumes, narrow pore size distributions, and superparamagnetic property. The nanocrystals can be well dispersed in a highly ordered 2D hexagonal mesostructured silica matrix. Moreover, pore sizes and magnetization values can be tunable by using cationic surfactants with different aliphatic hydrocarbon chain lengths and changing amount of nanocrystals added, respectively. By studying binary cyt $c$ and BSA sorption on MSNs, it was found that high separation selectivity and release percentage of cyt $c$ can be achieved. Small particle size, high surface area, and numerous accessible pore of MSNs render a fast adsorption rate, high adsorption capacity, and high removal efficiency. High magnetization values and superparamagnetic property of MSNs provide a convenient method for them to be promptly removed from solution, and quickly re-dispersed in solution by applying or removing an external magnetic field. The separation approach proposed in this study offers a very convenient and useful means to separate biomolecules (proteins, peptides, etc.) with different molecular size and weight. The materials synthesized in this study may also have potential applications in targeted drug/gene delivery, controlled release, biosensing, and cell imaging.

\section{Experimental}

Chemicals: 1-octadecene (90\%), 1,2-hexadecanediol (90\%), chloroform $(99 \%)$, myristyltrimethylammonium bromide $\left(\mathrm{C}_{14} \mathrm{TAB}\right.$, $99 \%$ ), hexadecyltrimethylammonium bromide $\left(\mathrm{C}_{16} \mathrm{TAB}, 95 \%\right)$, octadecyltrimethylammonium bromide $\left(\mathrm{C}_{18} \mathrm{TAB} 97 \%\right)$, TEOS $(99 \%)$, sodium hydroxide (98\%), ammonia solution (25\%), cyt $c$ from bovine heart (cyt $c, 95 \%$ ), albumin from bovine serum (BSA, 98\%) were purchased from Aldrich. Iron stearic acid [Fe(SA) $)_{3},>98.5 \%$ ] was purchased from Jinghe Chemical Ltd., China. All chemicals were used as received without purification.

Synthesis of Monodisperse Superparamagnetic $\mathrm{Fe}_{3} \mathrm{O}_{4}$ Nanocrystals: $\mathrm{Fe}(\mathrm{SA})_{3}(2.0 \mathrm{mmol}), 1,2$-hexadecanediol $(9.0 \mathrm{mmol})$, and $10 \mathrm{~mL}$ of 1 -octadecene were heated and stirred until it became a homogeneous mixture. The resulting homogeneous mixture was heated and crystallized under static conditions at $250^{\circ} \mathrm{C}$ in a Teflon-lined autoclave for $6-$ $12 \mathrm{~h}$. The synthesized mixture was then allowed to cool down to room temperature. $\mathrm{Fe}_{3} \mathrm{O}_{4}$ nanocrystals were washed with the mixture of 
ethanol and chloroform for three to four times. The precipitate was collected by centrifuging at $4750 \mathrm{rpm}$ for $20 \mathrm{~min}$ and suspended in $5 \mathrm{~mL}$ of chloroform.

Synthesis of Magnetic Nanocomposites: In a typical experiment, $2.0 \mathrm{~mL}$ of $\mathrm{Fe}_{3} \mathrm{O}_{4}$ nanocrystals dispersed in chloroform $\left(30 \mathrm{mg} \mathrm{mL}^{-1}\right)$ was added to $10 \mathrm{~mL}$ of aqueous solution containing $0.2 \mathrm{~g}$ of $\mathrm{C}_{16} \mathrm{TAB}$ (or $\mathrm{C}_{18} \mathrm{TAB}$ ). After vigorous stirring of the resulting solution, a homogeneous oil-in-water microemulsion was obtained. Heating at $65^{\circ} \mathrm{C}$ for $20 \mathrm{~min}$ induced the evaporation of chloroform and led to the formation of aqueous phase dispersed nanocrystals.

$\mathrm{C}_{16} \mathrm{TAB}$ (or $\left.\mathrm{C}_{18} \mathrm{TAB}\right)(0.05 \mathrm{~g}$ ) and $0.7 \mathrm{~mL}$ of $\mathrm{NaOH}(2 \mathrm{M})$ were dissolved in $86 \mathrm{~mL}$ of water and stirred at room temperature. Then $10 \mathrm{~mL}$ of the as-synthesized aqueous phase monodisperse $\mathrm{Fe}_{3} \mathrm{O}_{4}$ nanocrystals was added into the system, and the mixed solution was heated to $80^{\circ} \mathrm{C}$ and then $1.26 \mathrm{~g}$ of TEOS was introduced under vigorous stirring. After $2 \mathrm{~h}$ stirring, the light brown product was collected by filtration and dried at room temperature. To control the magnetization value, the amount of nanocrystals was varied while keeping the other reaction conditions constant. The products were denoted as MSNs- $\mathrm{C}_{16}-x$ (or MSNs- $\mathrm{C}_{18}-x$ ) where $x$ denotes the solution volume of $\mathrm{Fe}_{3} \mathrm{O}_{4}$ nanocrystals dispersed in chloroform.

For the synthesis of magnetic silica spheres with smaller pore size, $0.53 \mathrm{~g}$ of $\mathrm{C}_{14} \mathrm{TAB}$ and $2.8 \mathrm{~g}$ of $\mathrm{NH}_{3} \cdot \mathrm{H}_{2} \mathrm{O}(25 \%)$ were dissolved in $110 \mathrm{~mL}$ of water and stirred at $30^{\circ} \mathrm{C}$. Then $10 \mathrm{~mL}$ of as-synthesized aqueous phase monodisperse $\mathrm{Fe}_{3} \mathrm{O}_{4}$ nanocrystals (prepared by abovementioned method, but using $\mathrm{C}_{14} \mathrm{TAB}$ as a surfactant to transfer hydrophobic $\mathrm{Fe}_{3} \mathrm{O}_{4}$ nanocrystals from chloroform to aqueous phase) were added into the system, and $1.05 \mathrm{~g}$ of TEOS was introduced under vigorous stirring at $30^{\circ} \mathrm{C}$. After $24 \mathrm{~h}$ stirring, the light brown product was collected by filtration, dried at room temperature, and named by MSNs- $\mathrm{C}_{14}-x$. Similarly, $x$ denotes the volume of $\mathrm{Fe}_{3} \mathrm{O}_{4}$ nanocrystals chloroform solution and changes from 1.0 to $8.0 \mathrm{~mL}$.

For all cases using various surfactants as mentioned above, the resulting powders were washed by deionized water and extracted by refluxing with ethanol for $8 \mathrm{~h}$ to remove the surfactant templates completely.

Bioadsorption Isotherm Measurement and Binary Component Bioseparation: The size-selective adsorption of biomolecules on MSNs was investigated using cyt $c$ and BSA as model proteins.

For adsorption isotherm measurement, $20 \mathrm{mg}$ of MSNs was suspended in $4 \mathrm{~mL}$ of $50 \mathrm{mM}$ buffer solution $(\mathrm{pH}=9.6$ sodium bicarbonate buffer solution or $\mathrm{pH}=4.8$ citric acid buffer solution) with different cyt $c$ (from 0.12 to $4.5 \mathrm{~g} \mathrm{~L}^{-1}$ ) or BSA (from 1.5 to $15 \mathrm{~g} \mathrm{~L}^{-1}$ ) initial concentrations. The resulting mixture was placed into a water bath controlled at $30^{\circ} \mathrm{C}$ and continuously shaken for $96 \mathrm{~h}$, which was demonstrated to be long enough to reach the adsorption equilibrium. ${ }^{[16]}$ The MSNs were then removed from the suspension by an external magnetic field. The supernatant was analyzed by UV absorbance at 409 or $280 \mathrm{~nm}$ to determine the adsorbed amount of cyt $c$ or BSA, respectively. The adsorbed amount of cyt $c$ and BSA was calculated according to the following equation:

$q=\frac{V_{0}\left(C_{0}-C\right)}{W}$

where $q$ is the equilibrium adsorbed amount in the particles, $C_{0}$ and $C$ are the protein concentrations at initial and equilibrium solution, respectively, $V_{0}$ the volume of the initial protein solution, and $w$ is the weight of the adsorbent.

For binary component bioadsorption separation of cyt $c$ and BSA, $20 \mathrm{mg}$ of MSNs was suspended in $4 \mathrm{~mL}$ of $50 \mathrm{mM}$ sodium bicarbonate buffer solution $(\mathrm{pH}=9.6)$. The initial concentrations were fixed $\left(0.5 \mathrm{~g} \mathrm{~L}^{-1}\right)$ for cyt $c$, but varied from 1.5 to $4.5 \mathrm{~g} \mathrm{~L}^{-1}$ for BSA. In this concentration range, no interference between cyt $c$ and BSA was found in determining the equilibrium concentration of cyt $c$ and BSA by UV absorbance at 409 or $280 \mathrm{~nm}$, respectively. The separation experiment was carried out at $30^{\circ} \mathrm{C}$ and adsorption equilibrium time was $20 \mathrm{~min}$.
The selectivity of cyt $c$ adsorption was calculated according to the following equation:

Selectivity $=\frac{M_{\text {cytc }}}{M_{\text {cytc }}+M_{\mathrm{BSA}}}$

where $M_{\text {cytc }}$ and $M_{\mathrm{BSA}}$ are the molar amounts of cyt $c$ and BSA adsorbed on the MSNs, respectively. For desorption study, MSNs adsorbed cyt $c$ (and slight BSA) were transferred into high ionic strength buffer $(1.0 \mathrm{M} \mathrm{KCl})$ to release the adsorbed proteins.

Characterization: XRD measurements were performed on a Rigaku D/max-2550V diffractometer using Co $\mathrm{K} \alpha$ radiation at $30 \mathrm{kV}$ and $15 \mathrm{~mA}$. SEM images of samples coated with platinum were recorded on a JEOL 6300 microscope. TEM images were obtained by FEI Tecnai F20 and FEI Tecnai F30 electron microscope. The powder samples for the TEM measurements were suspended in ethanol and then dropped onto the $\mathrm{Cu}$ grids with holey carbon films. Nitrogen sorption isotherms of samples were obtained by a Quantachrome's Quadrasorb SI analyzer at $77 \mathrm{~K}$. Before the measurements were taken, the samples were degassed at $200^{\circ} \mathrm{C}$ for $12 \mathrm{~h}$ in vacuum. BET surface area was calculated using experimental points at a relative pressure of $P / P_{0}=0.05-0.25$. The total pore volume was calculated by the $\mathrm{N}_{2}$ amount adsorbed at the highest $P / P_{0}\left(P / P_{0} \approx 0.99\right)$. The pore size distribution was calculated by the Barrett-Joyner-Halenda $(\mathrm{BJH})$ method.

An UV-Vis absorbance spectrophotometer (JASCO-V550) was used to determine the concentration of cyt $c$ and BSA in supernatant solution at 409 and $280 \mathrm{~nm}$, respectively. Magnetization measurements were carried out using a Magnetic Property Measure System (MPMS, Quantum design) under magnetic fields up to 10000 Oe and at $300 \mathrm{~K}$

Received: March 14, 2008 Published online: September 29, 2008

[1] C. T. Kresge, M. E. Leonowicz, W. J. Roth, J. C. Vartuli, J. S. Beck, Nature 1992, 359, 710.

[2] D. Zhao, J. Feng, Q. Huo, N. Melosh, G. H. Fredrickson, B. F. Chmelka, G. D. Stucky, Science 1998, 279, 548.

[3] U. Ciesla, F. Schüth, Microporous Mesoporous Mater. 1999, 27, 131.

[4] J. Y. Ying, C. P. Mehnert, M. S. Wong, Angew. Chem, Int. Ed. 1999, 38, 56.

[5] B. G. Trewyn, C. M. Whitman, V. S. Y. Lin, Nano Lett. 2004, 4, 2139.

[6] K. Suzuki, K. Ikari, H. Imai, J. Am. Chem. Soc. 2004, 126, 462.

[7] Y. Han, J. Y. Ying, Angew. Chem, Int. Ed. 2005, 44, 288

[8] J. Y. Ying, Chem. Eng. Sci. 2006, 61, 1540.

[9] H. Takahashi, B. Li, T. Sasaki, C. Miyazaki, T. Kajino, S. Inagaki, Chem. Mater. 2000, 12, 3301

[10] Y. J. Han, G. D. Stucky, A. Butler, J. Am. Chem. Soc. 1999, 121, 9897.

[11] C. Y. Lai, B. G. Trewyn, D. M. Jeftinija, K. Jeftinija, S. Xu, S. Jeftinija, V. S. Y. Lin, J. Am. Chem. Soc. 2003, 125, 4451.

[12] D. R. Radu, C. Y. Lai, K. Jeftinija, E. W. Rowe, S. Jeftinija, V. S. Y. Lin, J. Am. Chem. Soc. 2004, 126, 13216.

[13] I. Slowing, B. G. Trewyn, V. S. Y. Lin, J. Am. Chem. Soc. 2006, 128, 14792.

[14] S. Giri, B. G. Trewyn, M. P. Stellmaker, V. S. Y. Lin, Angew. Chem, Int. Ed. 2005, 44, 5038.

[15] S. Z. Qiao, H. Djojoputro, Q. H. Hu, G. Q. Lu, Prog. Solid State Chem 2006, 34, 249.

[16] S. Z. Qiao, C. Z. Yu, W. Xing, Q. H. Hu, H. Djojoputro, G. Q. Lu, Chem. Mater. 2005, 17, 6172.

[17] H. H. P. Yiu, C. H. Botting, N. P. Botting, P. A. Wright, Phys. Chem. Chem. Phys. 2001, 3, 2983. 
[18] M. E. Davis, Nature 2002, 417, 813.

[19] M. Hartmann, Chem. Mater. 2005, 17, 4577.

[20] A. Katiyar, N. G. Pinto, Small 2006, 5, 644.

[21] R. Tian, H. Zhang, M. L. Ye, X. G. Jiang, L. H. Hu, X. Li, X. H. Bao, H. F. Zou, Angew. Chem, Int. Ed. 2007, 46, 962.

[22] L. Ji, A. Katiyar, N. G. Pinto, M. Jaroniec, P. G. Smirniotis, Microporous Mesoporous Mater. 2004, 75, 221.

[23] A. Katiyar, L. Ji, P. G. Smirniotis, N. G. Pinto, Microporous Mesoporous Mater. 2005, 80, 311.

[24] A. B. Bourlinos, A. Simopoulos, N. Boukos, D. Petridis, J. Phys. Chem. B 2001, 105, 7432.

[25] A. F. Gross, M. R. Diehl, K. C. Beverly, E. K. Richman, S. H. Tolbert, J. Phys. Chem. B 2003, 107, 5475.

[26] J. Kim, J. E. Lee, J. Lee, Y. Jang, S. W. Kim, K. An, J. H. Yu, T. Hyeon, Angew. Chem, Int. Ed. 2006, 45, 4789.

[27] P. Wu, J. Zhu, Z. Xu, Adv. Funct. Mater. 2004, 14, 345.

[28] L. Zhang, S. Z. Qiao, Y. G. Jin, Z. G. Chen, H. C. Gu, G. Q. Lu, $A d v$. Mater. 2008, 20, 805 .

[29] Z. H. Sun, L. F. Wang, P. P. Liu, S. C. Wang, B. Sun, D. Z. Jiang, F. S. Xiao, Adv. Mater. 2006, 18, 1968

[30] M. Arruebo, M. Galán, N. Navascués, C. Téllez, C. Marquina, M. R. Ibarra, J. Santamaría, Chem. Mater. 2006, 18, 1911.

[31] A. H. Lu, W. C. Li, A. Kiefer, W. Schmidt, E. Bill, G. Fink, F. Schüth, J. Am. Chem. Soc. 2004, 126, 8616.

[32] W. R. Zhao, J. L. Gu, L. X. Zhang, H. R. Chen, J. L. Shi, J. Am. Chem. Soc. 2005, 127, 8916.

[33] Y. S. Lin, S. H. Wu, Y. Hung, Y. H. Chou, C. Chang, M. L. Lin, C. P. Tsai, C. Y. Mou, Chem. Mater. 2006, 18, 5170.

[34] J. Kim, J. E. Lee, J. Lee, J. H. Yu, B. C. Kim, K. An, Y. Hwang, C. H. Shin, J. G. Park, J. Kim, T. Hyeon, J. Am. Chem. Soc. 2006, 128, 688.

[35] A. Bee, R. Massart, S. Neveu, J. Magn. Magn. Mater. 1995, 149, 6.

[36] A. L. Willis, N. J. Turro, S. O'Brien, Chem. Mater. 2005, 17, 5970.

[37] B. L. Cushing, V. L. Kolesnichenko, C. J. O'Connor, Chem. Rev. 2004, 104, 3893.
[38] C. Liu, B. Zou, A. J. Rondinone, Z. J. Zhang, J. Phys. Chem. B 2000, 104, 1141.

[39] K. Woo, H. J. Lee, J. P. Ahn, Y. S. Park, Adv. Mater. 2003, 15, 1761.

[40] N. Moumen, M. P. Pileni, J. Phys. Chem. 1996, 100, 1867.

[41] X. Wang, J. Zhuang, Q. Peng, Y. Li, Nature 2005, 437, 121.

[42] H. Deng, X. Li, Q. Peng, X. Wang, J. Chen, Y. Li, Angew. Chem. 2005, 117, 2841; Angew. Chem, Int. Ed. 2005, 44, 2782.

[43] J. Park, K. An, Y. Hwang, J. G. Park, H. J. Noh, J. Y. Kim, J. H. Park, N. M. Hwang, T. Hyeon, Nat. Mater. 2004, 3, 891.

[44] S. Sun, H. Zeng, D. B. Robinson, S. Raoux, P. M. Rice, S. X. Wang, G. Li, J. Am. Chem. Soc. 2004, 126, 273

[45] J. Park, J. Joo, S. G. Kwon, Y. Jang, T. Hyeon, Angew. Chem, Int. Ed. 2007, 46, 4630

[46] H. Fan, K. Yang, D. M. Boye, T. Sigmon, K. J. Malloy, H. Xu, G. P. López, C. J. Brinker, Science 2004, 304, 567.

[47] H. Fan, E. W. Leve, C. Scullin, J. Gabaldon, D. Tallant, S. Bunge, T. Boyle, M. C. Wilson, C. J. Brinker, Nano Lett. 2005, 5, 645.

[48] H. Fan, Z. Chen, C. J. Brinker, J. Clawson, T. Alam, J. Am. Chem. Soc. 2005, 127, 13746.

[49] G. Büchel, K. K. Unger, A. Matsumoto, K. Tsutsumi, Adv. Mater. 1998, 10,1036

[50] Y. R. Cheng, H. P. Lin, C. Y. Mou, Phys. Chem. Chem. Phys. 1999, 1, 5051.

[51] I. Szleifer, A. B. Shaul, W. M. Gelbart, J. Chem. Phys. 1986, 85, 5345

[52] Y. Wan, D. Y. Zhao, Chem. Rev. 2007, 107, 2821.

[53] Q. Cai, Z. S. Luo, W. Q. Pang, Y. W. Fan, X. H. Chen, F. Z. Cui, Chem. Mater. 2001, 13, 258.

[54] A. Vinu, V. Murugesan, O. Tangermann, M. Hartmann, Chem. Mater. 2004, 16, 3056

[55] A. Vinu, C. Streb, V. Murugesan, M. Hartmann, J. Phys. Chem. B 2003, 107, 8297.

[56] L. W. Kriel, V. L. Jimenez, K. J. Balkus, J. Mol. Catal. B 2000, 10, 453.

[57] I. Slowing, B. G. Trewyn, V. S. Y. Lin, J. Am. Chem. Soc. 2007, 129, 8845 